\title{
sciendo
}

DOI 10.2478/sbe-2018-0028

SBE no. 13(2) 2018

\section{ASSESSING THE IMPACT OF TECHNOLOGY ADOPTION ON HUMAN TOUCH ASPECTS IN HEALTHCARE SETTINGS IN MAURITIUS}

\author{
RATNA Catriona Planel \\ Faculty of Law \& Management, University of Mauritius \\ JUWAHEER Roubina \\ Faculty of Law \& Management, University of Mauritius \\ PUDARUTH Sharmila \\ Faculty of Law \& Management, University of Mauritius
}

\begin{abstract}
:
This paper investigates the impact of technology adoption on human touch aspects in healthcare settings in Mauritius. Unstructured interviews, focus group discussions and overt observations were carried out in two phases with 27 healthcare professionals and 42 healthcare customers in the private sector over a period of five months as part of an exploratory study, followed by a pilot study where a survey was carried out among 31 participants who have also been exposed to private healthcare services in Mauritius. Survey findings have depicted that technology implementation in healthcare settings can represent a direct threat to human touch aspects. Although the outcome of service remains very important, the delivery of same service in terms of how, when and by whom it was delivered has been seen to be as important. Healthcare customers are normally in a vulnerable state requiring appropriate human touch in the service delivery. Moreover, they also expect fast, efficient and effective services which eventually create a pressing need for consequent use of technology. Therefore, the balance between technology and human touch aspects was found to be a determinant of service quality enforcement and customer satisfaction for healthcare customers. This paper demonstrates that implementing technology in healthcare nowadays is inevitable for proper service delivery, however, it is imperative to preserve human touch aspects at all times during health service encounters. This pioneer study also acts as a guide for health care practitioners to derive the best strategies to maintain a good equilibrium between technology adoption and human touch aspects in all healthcare services in the context of developing state such as Mauritius.
\end{abstract}

Key words: Technology, Healthcare, Mauritius, Human touch 


\section{Introduction}

In this information technology savvy world, technology adoption is highly encouraged in all organizations irrespective of their nature of business or operating sector. In a similar vein, in the context of healthcare, technology is omnipresent and very little in the field of medicine has not been affected by new technology as clearly stated by Moseley (2005). Increasingly, healthcare providers are adopting various technologies to meet the complexities of today's healthcare demands, regulatory requirements, and ever rising consumers' expectations (Olivia and Matthew, 2010). As far as customers are concerned, the primary aim of all healthcare organizations is to provide quality services to ensure customer satisfaction in a consistent manner.

This implies effort and acceptance by the whole organization to readily adopt and make use of technologies for greater organizational results. There are many factors that should be considered when implementing new technological systems such as setting up the right infrastructure, collecting the appropriate data for processing, performing the necessary training of staff amongst others. Failing to respect the requirements can eventually cause great loss for the business entities. Nevertheless, Robert et al. (2009) have identified several shortcomings in many studies of technology adoption including most notably the perspective which viewed these adoptions as oneoff events rather than a process; the conceptualization of organisations as unitary actors; the relative neglect of politics and power in healthcare organisations and the perception of individuals within organisations as passive recipients of innovations.

Despite the fact regarding the significance of technology adoption in terms of faster services and enhanced communication, the rapidly evolving nature of technology can however create gaps if the adopters are not able to properly integrate those technologies into their business processes and corporate culture. In this respect, this paper focuses on the impact on human touch aspects in making use of technology when providing healthcare services in private healthcare settings in Mauritius. It also aims to expose the extent to which the lack of human touch aspects contributes to posit a gap pertaining to the adoption of technology. It investigates how such adoption can change the relationships and interactions between healthcare providers and receivers. This paper also sheds some light on some possible solutions to enhance technology acceptance and at the same time, this pioneer study fills the literature gap in the established literature pertaining to technology adoption for healthcare providers of developing states.

\section{Major Technological Changes in Healthcare: Glimpses in the Mauritian Context}

Over the years, because of the increase in the number of competitors as well as with the rapid advancement in technology, there was no other choice for healthcare organizations than to evolve in a way to adapt to these new technology trends. As such most private healthcare organizations nowadays offer the latest services in the 
different fields associated to healthcare while making use of technology as far as possible in the context of Mauritius. Apollo Bramwell Hospital in Mauritius for instance provides facilities such as telemedicine to bridge geographical distances and provides far distant consultations primarily (Apollo Bramwell, 2015a). Moreover, the hospital provides for Robotic Assisted Surgery services using the "Da Vinci System" which features a magnified 3D high-definition vision system and tiny wristed instruments that bend and rotate far greater than the human wrist. Such mechanism enables a surgeon to operate with enhanced vision, precision, dexterity and control, he or she is fully in control of the system which translates his or her hand movements into smaller, more precise movements of tiny instruments inside the body (Apollo Bramwell, 2015b).

On the other side, other private Healthcare firms offer more specialized services such as diagnosis and treatment of infertility at Harvey Street Fertility Center (Harley Street Fertility, 2013) or Hair Grafting services at the "Centre de Chirurgie Esthétique de L'Ocean Indien" (Centre de Chirurgie Esthétique de L’Ocean Indien, 2014) in Mauritius. These new advanced facilities or treatments demonstrate high technology adoption with respect to the healthcare services offered in Mauritius.

With the use of technology, communicating information, making a patient's follow-up and even marketing services offered become more effective and efficient. According to the Board Of Investment (BOI) Mauritius, the Healthcare infrastructure together with associated measures and entities have undergone a rapid growth over the last years. For example in 2013, there was a total of 26 private clinics operating in Mauritius (BOI, 2013) as compared to 20 in 2011 (BOI, 2011). Moreover in 2012, there was a total of 21,346 foreign patients (BOI, 2014) as compared to approximately 10,000 in 2010 and it is expected to attract 100,000 foreign patients annually by 2020 (BOI, 2011). This shows that the demand for private healthcare services is undergoing a consequent increase making the use of technology even more important.

However, there is an important factor that comes into play in healthcare delivery which is the human touch aspects normally closely related to the emotions involved. In an earlier study conducted by Maynard (1992), emotion is central to the communication taking place in healthcare organizations which confirms that considering this aspect is very important for the well-being of both the healthcare receivers and providers. As technology causes transformations in healthcare, it is crucial to explore its impact on customers' emotions and eventually how those same emotions are handled by maintaining a reasonable human touch level.

\section{Objectives of the study}

The primary aim of this paper is to obtain a good understanding of the impact of technology adoption on human touch aspects in healthcare settings in Mauritius. The motive is to help private healthcare organizations in finding ways to limit such impact at all levels to eventually ensure service quality enforcement and customer satisfaction. 
This paper explores real life settings, environment and experiences of both healthcare providers and receivers in order to fulfill its objectives which are as follows:

- To expose the major factors related to technology adoption that directly or indirectly affect human touch aspects in healthcare settings

- To assess customers` reactions and satisfaction level due to a lack of human touch throughout the healthcare service delivery

- To determine the right measures, attitudes and behaviors for healthcare professionals to adopt to preserve human touch aspects in a fast changing technological environment

\section{Literature Review}

\section{Technology adoption in healthcare}

Evolution of technology is a never ending process causing fast and tremendous changes to all aspects of healthcare in general. For instance the introduction of computer and internet technology has not only transformed how medical and surgical procedures can be conducted, but also created unimaginable avenues for managing healthcare operations (Olivia and Matthew, 2010). With the Internet, there is death of distance, information remains available all the time and physical displacement to a healthcare centre is no more mandatory. Technology studies within the healthcare industry mainly focuses on hospital employees' management decision (Levaggi et al., 2009; Li and Benton, 2006), organization's financial performance (Menachemi et al., 2006), and consumer acceptance (Schur and Berk, 2008). Thus said the incremental use of technology to facilitate medical services requires a good analysis and comprehension of its impact on all direct and indirect aspects of healthcare. This will help organizations to better plan their procedures, derive the best strategies to adapt to emerging technologies and ensure customer satisfaction at all times.

Nowadays, one of the best ways to integrate technology into an organizational structure is to consider the implementation of an enterprise resource planning (ERP) software. One of the ERP systems characteristics is its ability to automate and integrate organizations' business processes (Fui-Hoon Nah and Lau, 2001). Moreover, the high customizability and extensibility of such system make it easier to adapt to technology changes rapidly and with minimal effect on normal activities which is essential in a critical sector like healthcare. Although integration success in ERP implementations is questionable (Themistocleous et al. 2001), ERP systems functionality and integration however greatly improved over time to fit more specific sectors. For instance a Hospital Information System (HIS) is an ERP system that has been developed exclusively for the healthcare sector. The HIS is a computer-based system designed to facilitate the management of the administrative and medical information within a hospital (Vassilios et al., 2008). The main aim of the system is improvement in the quality of the care provided (Degoulet and Fieschi, 1997). However, due to the high implementation cost of the HIS, not all healthcare organizations consider the latter for purchase. Normally only large healthcare 
organizations implement the HIS, smaller healthcare organizations prefer to purchase other more affordable ERP systems and customizing them as per their requirements. This is confirmed by Li and Benton (2006) who argued that large hospital systems tend to invest more in tools and equipments for providing technology-related services than smaller hospitals. Therefore, the difference between the various healthcare organizations lies mostly on how they implement and adapt to technology rather than if they implement it.

\section{Human Touch Aspects and Associated Challenges}

Keeping a good relationship with the customers is crucial for the success of the business because it has the potential to increase customer retention rates (Ndubisi, 2011). In healthcare sectors, relationship with a customer depends highly on how care is provided, the associated investment and the outcome. As many of the activities in healthcare organizations include life-changing events, such as birth, death, and facing the inevitability of mortality (Brunton, 2005), this already suggests that human touch aspects have a major role in maintaining the best relationship with the customers. Considering the high increase in technology adoption makes it therefore crucial to perform and in-depth analysis of its impact on the relationship with customers, not only regarding the way of communicating but also regarding how care is provided and both the physical and emotional outcomes.

Indeed, communication is faster with the adoption of technology, but however, the same communication is considered as less personal (Rozaine, 2014). Moreover, the services themselves are intangible therefore cannot be seen or touched (Jim, 1997), therefore, healthcare providers need to concentrate on aspects that will help the customers to experience the services in the best conditions. Emergence and adoption of new technologies do not make this task easy, for example, while computerizing patients' medical records, the whole interaction and processes will depend mostly if not fully on the data fed in the system which can cause the latter to become the center of attention. In this case there is a higher risk for the emotional needs of the customers to be neglected. This shows that the more technology is being adopted, the more it becomes a challenge to maintain human touch aspects. Nevertheless, such challenge can be eased if proper evaluation of each technology adoption and its mapping on the organization business processes is considered from a holistic approach.

One of the reasons according to Wyatt and Wyatt (2003) to make an evaluation of hospital information systems is that it will contribute to the avoidance of negative effects on the processes of care provided to patients. This exposes the fact that implementation of technology can have a negative impact on the processes of patients' care. Therefore, the outcomes actually depends primarily on how technologies are planned, implemented and maintained and if appropriate measures are taken to maintain higher focus on the customer rather than on the systems even though the whole interaction during the healthcare services delivery relies mostly on the latter. 


\section{Research Methodology}

An exploratory study was carried out in two phases and involved unstructured interviews, focus group discussions and overt observations with 27 healthcare professionals and 42 healthcare customers in the private sector over a period of five months. The study was undertaken so that the normal business processes taking place in private healthcare centers and the actual expectations of customers with respect to healthcare services were known and understood in Mauritius. The qualitative data obtained was critically analysed and common patterns within the participants' responses were categorised and later quantified. Eventually, a questionnaire was set using the categories as variables and tested during a pilot study over a period of four months involving 31 participants who have also been exposed to private healthcare services in Mauritius. Information collected was then critically analysed in order to address the objectives of the exploratory study.

\section{Sampling Plan}

The different target audiences, the size of the selected population and the data collection methods have been chosen in accordance with the objectives of this research for both the exploratory study and the pilot study (Table 1 and Table 2).

Table 1: Exploratory study phases 1 and 2 sampling plan

\begin{tabular}{|c|c|c|c|c|c|}
\hline & Audience & $\begin{array}{l}\text { Exploratory } \\
\text { Study Phase } 1 \text { - } \\
\text { No. of } \\
\text { participants }\end{array}$ & $\begin{array}{l}\text { Exploratory } \\
\text { Study Phase } 2 \text { - } \\
\text { No. of } \\
\text { participants }\end{array}$ & $\begin{array}{l}\text { Data Collection } \\
\text { Method/s }\end{array}$ & Data type \\
\hline 1 & \multicolumn{5}{|c|}{ Healthcare organization staff } \\
\hline a & $\begin{array}{l}\text { Physician } \\
\text { assistants, Nurses }\end{array}$ & 3 & 6 & $\begin{array}{l}\text { Unstructured face to } \\
\text { face interviews, focus } \\
\text { group discussions } \\
\text { and overt } \\
\text { observations }\end{array}$ & Qualitative \\
\hline $\mathrm{b}$ & $\begin{array}{l}\text { Administration } \\
\text { affairs (Patients } \\
\text { records), Customer } \\
\text { Service } \\
\text { representative, } \\
\text { Finance }\end{array}$ & 7 & 5 & $\begin{array}{l}\text { Unstructured face to } \\
\text { face interviews and } \\
\text { overt observations }\end{array}$ & Qualitative \\
\hline C & $\begin{array}{l}\text { IT professionals, } \\
\text { Marketing } \\
\text { professionals }\end{array}$ & 2 & 4 & $\begin{array}{l}\text { Unstructured face to } \\
\text { face interviews }\end{array}$ & Qualitative \\
\hline 2 & \multicolumn{5}{|c|}{ Healthcare organization customers (patients) } \\
\hline a & $\begin{array}{l}\text { Patients } \\
\text { undergoing } \\
\text { outpatient care }\end{array}$ & 8 & 12 & $\begin{array}{l}\text { Unstructured face to } \\
\text { face interviews }\end{array}$ & Qualitative \\
\hline $\mathrm{b}$ & Ex-Patients & 14 & 8 & $\begin{array}{l}\text { Unstructured face to } \\
\text { face interviews }\end{array}$ & Qualitative \\
\hline
\end{tabular}


Table 2: Pilot Study sampling plan

\begin{tabular}{|l|l|l|l|l|}
\hline & Audience of & $\begin{array}{l}\text { No. Data Collection Method/s } \\
\text { participants }\end{array}$ & Research type \\
\hline 1 & Academics & 10 & Survey & Quantitative \\
\hline 2 & Administrative officers & 7 & Survey & Quantitative \\
\hline 3 & Research assistants & 2 & Survey & Quantitative \\
\hline 4 & $\begin{array}{l}\text { Dependents } \\
\text { undergraduate } \\
\text { students): inpatient } \\
\text { care }\end{array}$ & 8 & Survey & Quantitative \\
\hline 5 & Others & 4 & Survey & Quantitative \\
\hline
\end{tabular}

\section{Empirical Findings}

The data collected during the exploratory study and pilot study brought much insight on the different aspects of private healthcare services in Mauritius including the general business processes, personal experiences of customers, factors of service quality, technology adoption procedures and preferences among others.

The three main categories applicable to private healthcare centers in Mauritius and regarding technology adoption are:

1. Organizations fully making use of technology in their processes

2. Organizations partly making use of technology in their processes

3. Organizations not making use of technology in their processes

At least one private healthcare center in each of the above mentioned categories has been visited in order to see the settings and experience the services as far as possible by learning from the customers` experiences.

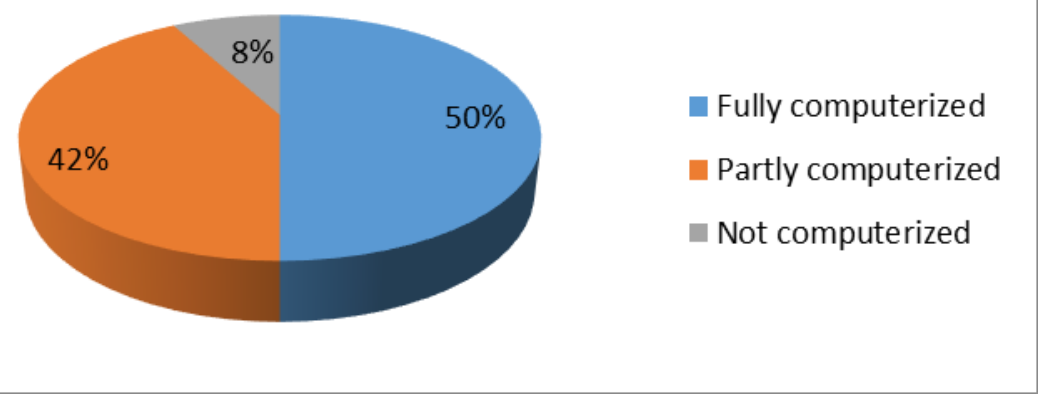

Figure 1: Preferences of customers regarding technology adoption in healthcare services

Empirical estimates have demonstrated that the majority of participants (50\%) prefer fully computerized services when purchasing private healthcare services. However, this value is very close to the percentage of the participants who prefer a fair use only of technology (42\%) in the health service delivery. This small difference 
suggests that while the use of technology is indeed expected by the customers, the extent of its use however is for debate.

Table 3 below provides the primary reasons discussed by the participants about their preference regarding fully computerized healthcare services.

Table 3: Primary reasons discussed by the participants (healthcare customers) about their preference for fully computerized healthcare services

\begin{tabular}{|c|c|c|}
\hline Code & Reasons discussed & Details \\
\hline A1 & Fast services & $\begin{array}{ll}\text { - } & \text { Admission and discharge formalities } \\
\text { - } & \text { Access to medical history for returning customers } \\
\text { - } & \text { Medical investigations }\end{array}$ \\
\hline $\mathrm{A} 2$ & Increased communication means & $\begin{array}{ll} & \text { Emails } \\
\text { - } & \text { Online requests from website } \\
\text { - } & \text { Social networks/ online forums }\end{array}$ \\
\hline A3 & On site facilities & $\begin{array}{ll}\text { - } & \text { Wifi } \\
\text { - } & \text { Smart TV } \\
\text { - } & \text { Automated bed/ wheelchairs } \\
\text { - } & \text { Digital security systems (doors/ compartments/ } \\
\text { floors) } & \\
\text { - CCTV }\end{array}$ \\
\hline A4 & Advance medical services & $\begin{array}{ll}\text { - } & \text { Robotic assisted surgery } \\
\text { - } & \text { Telemedicine }\end{array}$ \\
\hline A5 & $\begin{array}{l}\text { Reduction in human errors/ human } \\
\text { issues leading to best services }\end{array}$ & $\begin{array}{l}\text { - } \quad \text { Fatigue, stress, personal issues are not applicable } \\
\text { - } \quad \text { Use of picture archiving and communication system } \\
\text { (PACS) to automatically detect anomalies like cancer }\end{array}$ \\
\hline A6 & High brand image & $\begin{array}{ll} & \text { More visible (online) } \\
\text { - } & \text { Feel more confident/ Higher trust }\end{array}$ \\
\hline A7 & More competent personnel & $\begin{array}{l}\text { - Intensive training to efficiently use technological tools } \\
\text { - } \quad \text { Continuous training due to continuous changes in } \\
\text { technology }\end{array}$ \\
\hline A8 & Others & $\begin{array}{ll}\text { - } & \text { Personal preference } \\
\text { - } & \text { Modern/ sophisticate image/ Higher service quality } \\
\text { - } & \text { Paperless environment (customers who are "green- } \\
\text { conscious") }\end{array}$ \\
\hline
\end{tabular}

Survey findings have also depicted that the majority of participants $(90.9 \%)$ prefer fully computerized healthcare systems because it allows for faster services (A1) at all levels involved. Likewise, $81.8 \%$ of the participants agree that fully computerized systems enable increase in communication means (A2) as well as increase in the competence of the healthcare personnel (A7). While many participants mentioned that they often do not have the time, the need and/or the interest to take advantage of the on-site facilities (A3) including internet, smart TV among others as per available, $63.6 \%$ of the overall participants however agree of their importance in reinforcing the brand value of the organization not only for the patients but for the visitors as well. Only a reasonably small percentage of participants $(22.7 \%)$ consider fully computerized 
healthcare services as a factor contributing to reinforce the brand image of a healthcare organization (A6) while the smallest percentage of participants $(18.2 \%)$ prefer fully computerized healthcare services mainly based on their own personal preferences and/or values (A8).

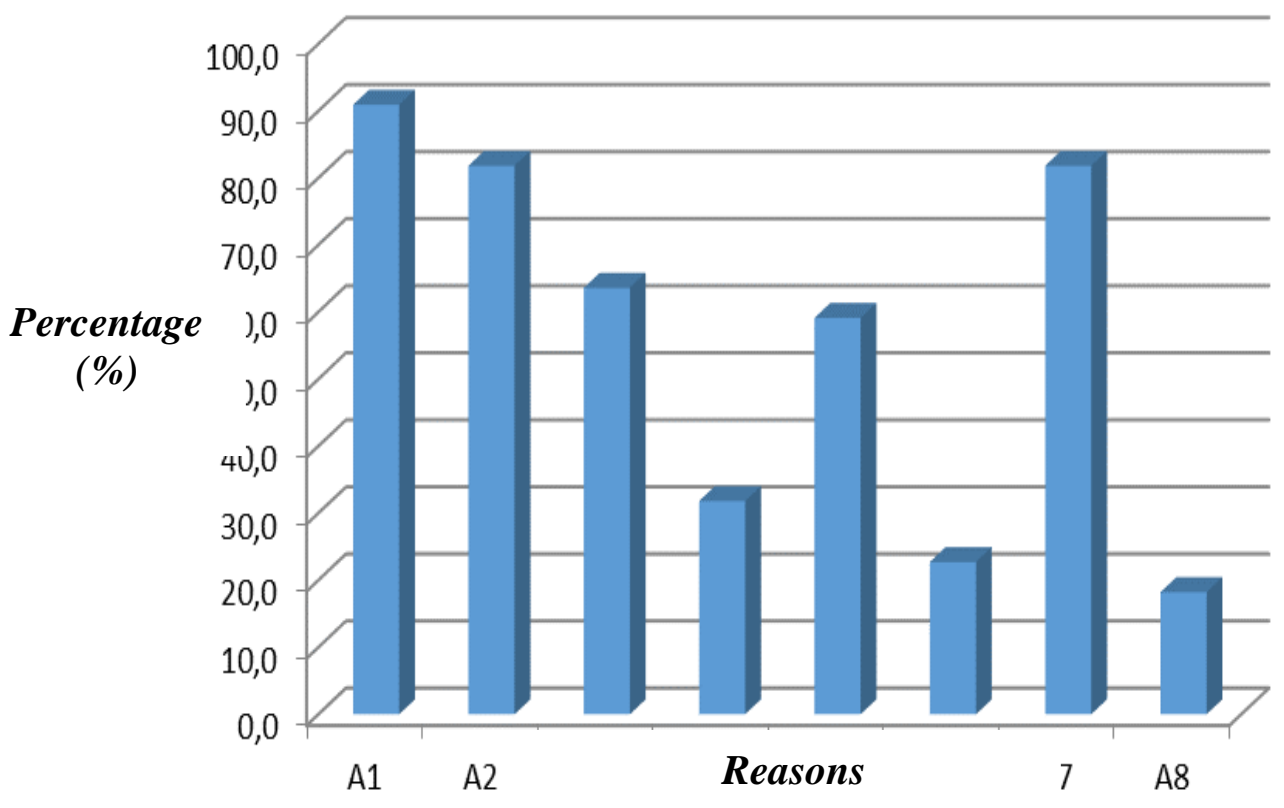

Figure 2: Reasons for customers to prefer fully computerized healthcare services

Table 4 below provides the primary reasons discussed by the participants about their preference for not being exposed to fully computerized healthcare services.

Table 4: Primary reasons discussed by the participants (healthcare customers) about their preference for not being exposed to fully computerized healthcare services

\begin{tabular}{|c|c|c|}
\hline Code & $\begin{array}{l}\text { Reasons discussed } \\
\text { (related to technology } \\
\text { adoption that directly or } \\
\text { indirectly affect human } \\
\text { touch aspects) }\end{array}$ & Details \\
\hline B1 & $\begin{array}{l}\text { Poor eye contact during } \\
\text { interaction }\end{array}$ & $\begin{array}{l}\text { Healthcare agents provide more attention to the computer } \\
\text { screen rather than to the customer/ patient }\end{array}$ \\
\hline B2 & $\begin{array}{l}\text { Poor attention to body } \\
\text { language of customer }\end{array}$ & $\begin{array}{l}\text { High use of technology creates distractions and thus prevent } \\
\text { healthcare agents from anticipating customers ' needs } \\
\text { (physical/ emotional) based on their body language }\end{array}$ \\
\hline B3 & $\begin{array}{l}\text { Less frequent human to } \\
\text { human interaction }\end{array}$ & Many processes become automated (no human involvement) \\
\hline B4 & $\begin{array}{l}\text { Shorter duration of human } \\
\text { to human interaction }\end{array}$ & Faster services $=$ faster interactions with customer/ patient \\
\hline B5 & Encourages high formality & $\begin{array}{l}\text { Standard business processes due to automation / Gives to the } \\
\text { customer the impression that it is all about a business }\end{array}$ \\
\hline
\end{tabular}




\begin{tabular}{|c|c|c|}
\hline & & transaction rather than a human experience \\
\hline B6 & More expensive treatment & $\begin{array}{l}\text { High license fees associated to computerized systems will have } \\
\text { to be absorbed primarily by the customers }\end{array}$ \\
\hline B7 & $\begin{array}{l}\text { Decreased trust/ poor } \\
\text { relationship with customer }\end{array}$ & $\begin{array}{l}\text { Less and/or shorter direct interactions does not give sufficient } \\
\text { room to build quality trust }\end{array}$ \\
\hline B8 & Fear and apprehensions & $\begin{array}{l}\text { Healthcare customers are normally in a vulnerable state, } \\
\text { interactions with humans are more reassuring than interactions } \\
\text { with machines. }\end{array}$ \\
\hline B9 & Medical errors & Problem/ error in computer system or infrastructure \\
\hline B10 & $\begin{array}{l}\text { Requires a reasonable } \\
\text { level of computer literacy }\end{array}$ & $\begin{array}{l}\text { Even at different levels, both the healthcare provider and } \\
\text { receiver will be exposed to the computerized system }\end{array}$ \\
\hline B11 & Frustration & $\begin{array}{l}\text { Less human contacts and faster automated services give less } \\
\text { opportunities for the customer to experience the healthcare } \\
\text { services optimally resulting in a high frustration to pay } \\
\text { expensive bills }\end{array}$ \\
\hline B12 & Others & Personal preference \\
\hline
\end{tabular}

90

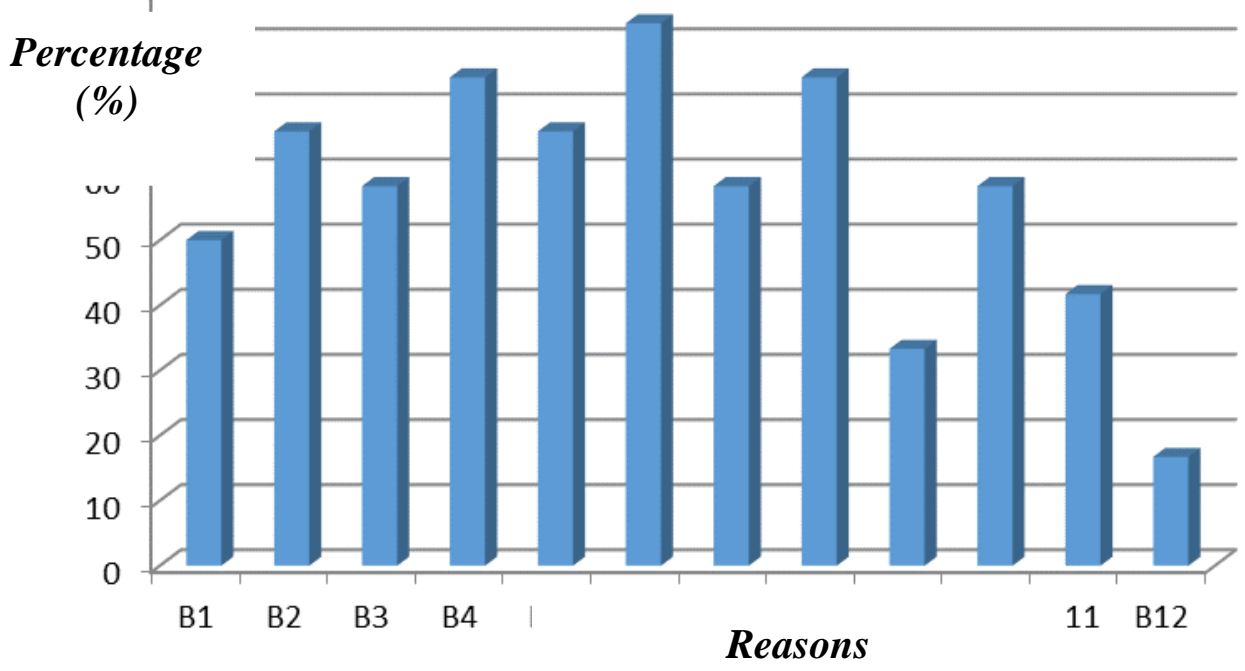

Figure 3: Reasons for customers to prefer only partially computerized healthcare services

Survey findings demonstrated that $50 \%$ of the participants consider a decrease in eye contact with an increase in the amount of computerized processes because the staff are then more focused on their computer screen than on the customer (B1). Moreover, $66.7 \%$ of the participants on their side recognized that high use of technology creates many distractions which in turn deviate the attention of the healthcare providers from important things such as the body language of customers (B2). Eventually the latter's physical and/or emotional needs are poorly or not attended. The same percentage of participants $(66.7 \%)$ agrees as well that full use of 
technology favors high formality during interactions as the processes are standard and for most automated (B5).

A similar percentage of participants (58.3\%) agree that a fully computerized healthcare system can decrease the frequency of human interactions (B3) and it also requires that all users including the customers/patients have to be reasonably computer literate (B10) which is not always the case. The highest percentage of participants (83.3\%) agrees that the treatment cost becomes more expensive (B6) with increase in use of technology in the processes. This eventually could cause much frustration (B11) as mentioned by $41.7 \%$ of the participants such as when having to pay an expensive bill following purchase of a service which has not been fully experienced for example due to poor human contact during the service delivery. The latter is confirmed by $75 \%$ of the participants who agrees that the duration of human to human interaction has indeed decreased (B4) due to faster services provided by technology. This inevitably suggests a poor or decreased trust between the healthcare provider and receiver (B7) as mentioned by $58.3 \%$ of the participants because faster services means less and/or shorter direct interactions which in turn does not favor building up quality trust. $75 \%$ of the participants mentioned that highly computerized healthcare services inspire them fear and apprehensions (B8) for many reasons such as the need to interact with machines rather than humans (one example mentioned: being 'greeted' by a queue management machine rather than a customer care representative). They also fear cases of medical errors (B9) in case of problems or errors in the computer system or infrastructure as confirmed by $33.3 \%$ of the participants.

The following Table 5 provides factors associated to the use of IT/Technology in private healthcare services in Mauritius and customers perception about such use based on their experiences.

\section{Table 5: Factors associated to the use of IT/Technology in private healthcare services in Mauritius}

\begin{tabular}{|l|l|}
\hline Code & Factors \\
\hline F1 & $\begin{array}{l}\text { Extensive use of IT/Technology causes the 'Human touch' aspect (friendliness/ empathy } \\
\text { etc...) to be adversely affected (e.g poor eye contact with customer due to focus on } \\
\text { computer screen) }\end{array}$ \\
\hline F2 & $\begin{array}{l}\text { Extensive use of IT/Technology guarantees that there won't be any medical errors } \\
\text { F3 }\end{array}$ \\
\hline F4 & $\begin{array}{l}\text { Extensive use of IT/Technology increases the sense of formality (rigid observance of } \\
\text { trustworthy }\end{array}$ \\
\hline F5 & $\begin{array}{l}\text { Good balance between use of IT/Technology and human touch aspect contributes in } \\
\text { providing the best healthcare services }\end{array}$ \\
\hline
\end{tabular}




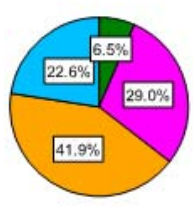

F1

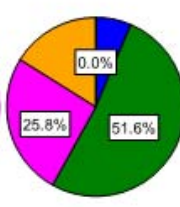

F2

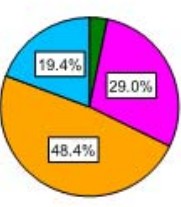

F3

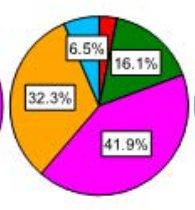

F4

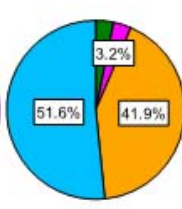

F5

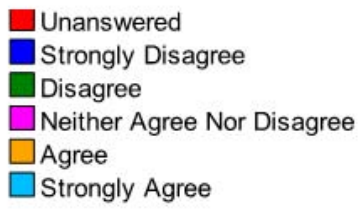

Strongly Agree

Figure 4: Customers' perception of private healthcare services involving the use of IT/Technology based on their experiences

Survey findings have demonstrated that $41.9 \%$ of the participants agreed that a good balance between use of IT/Technology and human touch aspect contributes in providing the best healthcare services (F5) compared to $51.6 \%$ who strongly agreed about same fact. Moreover $6.5 \%$ of the participants strongly disagreed about the fact that extensive use of IT guarantees that there won't be any medical errors (F2) compared to $51.6 \%$ who simply disagreed showing that the majority considered that the occurrence of medical errors is still possible even with the use of IT. A good majority of participants also admitted (41.9\% agreed/ $22.6 \%$ strongly agreed) that extensive use of IT causes the 'Human touch' aspect such as friendliness, empathy among others to be adversely affected (F1).

\section{Discussion and Managerial Implications}

The analyses have exposed that while technology is being implemented to enhance healthcare services, the way it is implemented however is actually determinant to the preservation of one very important aspect of healthcare which is human touch. The latter was found to have a key role in determining the level of customer satisfaction due to the sensitive nature of the services. This is reinforced by Tucker and Adams (2001) who suggested that patient satisfaction is predicted by factors relating to caring, empathy, reliability, and responsiveness which are for all related to human touch aspects. It was moreover found based on the participants experiences that their satisfaction level was directly proportional to the extent to which they have been able to see or experience the services positively despite the outcomes. For example the treatment may not have been a total success but a caring and empathic approach would help to forget or at least attenuate the sadness and/or deception.

As at this stage, the gap existing between those who are for a full use of technology and those who are only for a partial or limited use of it is very small and its implications should not be neglected. Based on the reasons provided by the customers, it is clear that technology and human touch aspects are both very important to provide for the best healthcare services. However the difference in nature of the two aspects can lead to adverse repercussions on service quality and eventually on customer satisfaction if they are not well implemented. For instance technology 
aspects call mostly for a virtual and automated relationship with the customer whereas human touch aspects call primarily for a direct and personal relationship with same customer. The contrast in requirements shows the extent to which extreme attention has to be given to ensure that both aspects do not affect or limit each other in any situations. Moreover customers place a great deal of importance on relationships in service experiences (Parasuraman et al. 1991) such that the rapid, less frequent and impersonal services favored by technology may not leave sufficient room to build up quality relationships.

Therefore one of the main challenges for management is to ensure a proper equilibrium between those aspects that are technology and human touch at all stages during healthcare delivery. One first measure could be for managers to understand staff perceptions regarding patient expectations and perceptions to see if there are gaps between the two and doing the necessary to close same gaps through training for example (Silvestro, 2005). In such case the healthcare professionals would be more apt to develop the necessary skills, knowledge, attitudes and behaviors to deal with customers irrespective of the degree and types of technology involved. Another measure could be to integrate a degree of human touch in all aspects of technology adoption despite standardization and automation of processes. Considering both aspects as one integrated entity working together for one purpose at all times would certainly favor a better relationship with the customer which in turn would favor greater satisfaction. Eventually these measures have to be weaved into the organization's culture as a good approach to smooth organizational changes as well as to ease adaptation to forthcoming technologies.

\section{Conclusion}

Even if technology is regarded as the primary key to delivering optimal healthcare services nowadays and in the future, this study has exposed that there are certain conditions involved. While technology adoption is highly recommended and important, maintaining human touch aspects is as important. This study has also showed that there still exist a lot of misunderstandings regarding the use of technology and its impact on human touch aspects. People love technology not necessarily because they make use of it but because they are aware of what it can do, however the fact remain that these are still controlled by humans. As such in this context, technology is acting as an increasingly imposing intermediary between the healthcare provider and receiver which can highly weaken the trust and relationship between them if compensating measures are not taken. Additionally the fact that more and more processes are becoming computerized and automated is causing a decrease in the time spent with the customers which in turn is lowering the chance of demonstrating any form of human touch during interactions.

Actually it was found that very simple things can dramatically change a whole customer's experience. For example the frustration and dissatisfaction expressed by 
many participants were primarily due to the expensive bills related to medical services which were not only of short durations but which also involved poor human contacts. Therefore it can be said that an empathic approach towards a customer could definitely compensate for many negative feelings which further reinforces the importance of human touch aspects when delivering healthcare services.

Hopefully this study will help healthcare organizations in Mauritius to understand the extreme importance of maintaining the right equilibrium between technology adoption and human touch aspects at all levels of service. This will eventually not only increase their chance to achieve high service quality and customer satisfaction but will also ensure that they are able to readily adapt to technological changes with minimal impact on human touch aspects.

\section{References}

Apollo Bramwell, (2015a) "Corporate website of Apollo Bramwell Hospital - Patient and visitor information". accessed 28th January 2017, Available at: <http://www.apollobramwell.com/patient_visitor_info>

Apollo Bramwell, (2015b) "Robotic Assisted Surgery - The Da Vinci System". accessed 28th January 2017, Available at: < http://www.apollobramwell.com/articles/110>

Brunton Margaret, (2005),"Emotion in health care: the cost of caring", Journal of Health Organization and Management, Vol. 19 Iss 4/5 pp. 340 - 354.

Degoulet, P. and Fieschi, M. (1997), Introduction to Clinical Informatics, Springer Verlag, New York, NY.

Fui-Hoon Nah, F. and Lee-Shang Lau, J. (2001), "Critical factors for successful implementation of ERP systems", Business Process Management Journal, Vol. 7 No. 3, pp. 285-96.

Harley Street Fertility, (2013), "Accurate diagnosis of the cause of infertility, prior to treatment, is the key to our success with fertility treatment". accessed 28th January 2017, Available at: < http://www.harleystreetfertility.com/en/treatments.html>

Jim Grieves Brian P. Mathews , (1997),"Healthcare and the learning service", The Learning Organization, Vol. 4 Iss 3 pp. 88 - 98

Levaggi, R., Morretto, M. and Rebba, V. (2009), "Investment decisions in hospital technology when physicians are devoted workers", Economics of Innovation and New Technology, Vol. 19 Nos 5/6, pp. 487-512.

Li, L. and Benton, W.C. (2006), "Hospital technologies and nurse staffing management decisions", Journal of Operations Management, Vol. 24 No. 5, pp. 676-91.

Maynard, D.W. (1992), "On clinicians co-implicating recipients' perspective in the delivery of diagnostic news", in Drew, P. and Heritage, J. (Eds), Talk at Work: Interaction in Institutional Settings, Cambridge University Press, Cambridge, MA, pp. 331-58.

Menachemi, N., Burkhardt, J., Shewchuk, R., Burke, D. and Brooks, R.G. (2006), "Hospital information technology and positive financial performance: a different approach to finding and ROI", Journal of Healthcare Management, Vol. 51 No. 1, pp. 41-58.

Moseley, G.B. III (2005), "Changing conditions for medical technology in the health care industry", paper presented at the OGI School of Science and Engineering, Beaverton, OR, 18 October, available at: http://cpd.ogi.edu/Seminars05/MoseleySeminarlndex.htm (accessed 13 September 2015). 
Ndubisi, N.O. (2011),"The effects of respect and rapport on relationship quality perception of customers of small healthcare firms", Asia Pacific Journal of Marketing and Logistics, Vol. 23 Iss 2 pp. 135 - 151.

Olivia F. Lee Matthew L. Meuter, (2010),"The adoption of technology orientation in healthcare delivery", International Journal of Pharmaceutical and Healthcare Marketing, Vol. 4 Iss 4 pp. 355 - 374

Parasuraman, A., Zeithaml, V. and Berry, L.L. (1991), "Understanding customer expectations of service", Sloan Management Review, Vol. 32 No. 3, pp. 39-48.

Rozaine (2014), "Technology makes communication less personal", <http://www.sundaytimes.Ik/141109/business-times/technology-makes-communicationless-personal-says-business-psychologist-126009.html>, accessed June 2015.

Schur, C. and Berk, M. (2008), "Views on health care technology: American consider the risks and sources of information", Health Affairs, Vol. 27 No. 6, pp. 1654-64.

Silvestro, R. (2005), "Applying gap analysis in the health service to inform the service improvement agenda",International Journal of Quality \& Reliability Management, Vol. 22 No. 3, pp. 215-33.

Tucker, J. III and Adams, S.R. (2001), "Incorporating patients' assessments of satisfaction and quality: an integrative model of patients' evaluations of their care", Managing Service Quality , Vol. 11 No. 4, pp. 272-86.

Vassilios P. Aggelidis Prodromos D. Chatzoglou , (2008),"Methods for evaluating hospital information systems: a literature review", EuroMed Journal of Business, Vol. 3 Iss 1 pp. $99-118$

Wyatt, J.C. and Wyatt, S.M. (2003), "When and how to evaluate health information systems?", International Journal of Medical Informatics, Vol. 69 Nos 2/3, pp. 251-9. 